\title{
Dossiê
}

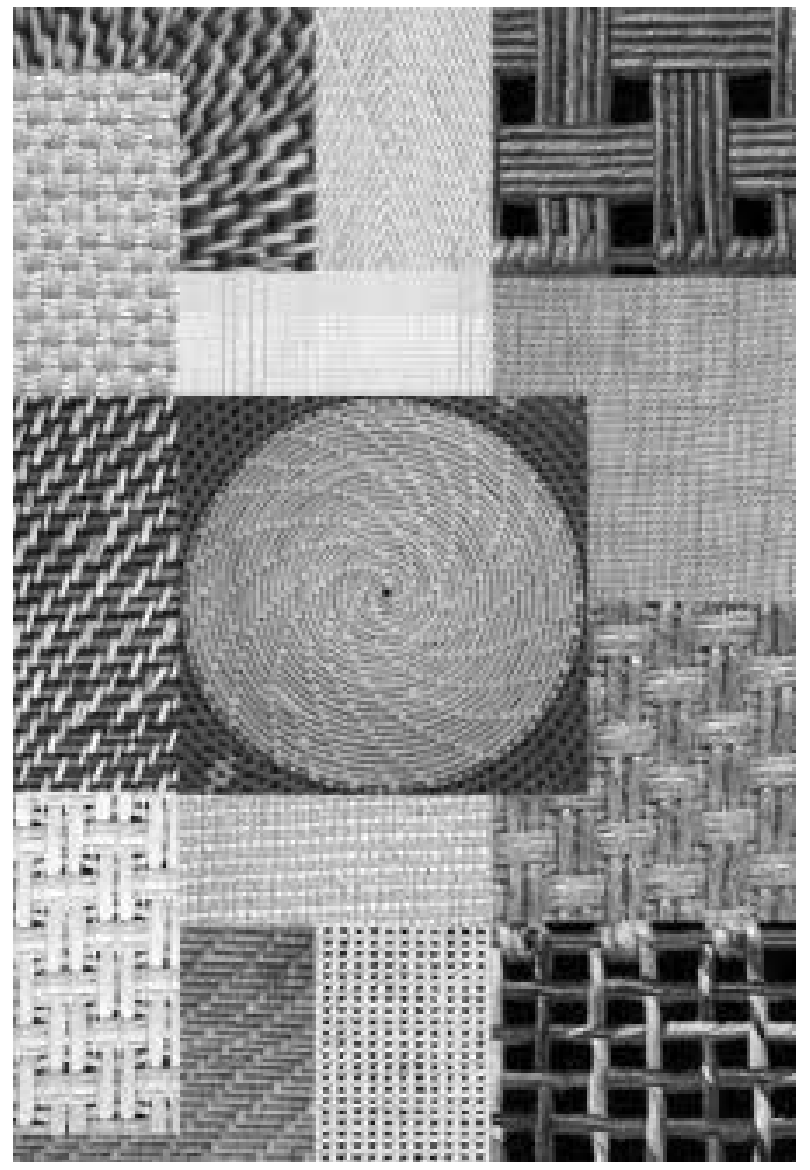




\section{Zyuganov: figura emblemática dos problemas dos comunistas russos pós-soviéticos ${ }^{1}$}

Angelo Segrillo

Doutor, UFF; M estre, Instituto Pushkin de M oscou

Resumo:

Este artigo analisa a trajetória política de Gennadii Zyuganov, o líder do Partido Comunista da Federação Russa. Procura mostrar como na carreira de Zyuganov estão refletidas as principais contradições e os dilemas por que passa o movimento comunistana Rússiaatual. Palavras-chave: Zyuganov; PCFR; Comunismo.
ABSTRACT:

This article analyzes the political career of Gennadii Zyuganov, the leader of the Communist Party of the Russian Federation. Zyuganov's actions and speeches highlight the contradictions and dilemmas which the Russian communist movement has to face nowadays. Keywords: Zyuganov; CPRF; Communism.

Gennadii Zyuganov não é um nome muito familiar aos brasileiros, mas é conhecido de qualquer russo. Trata-se do líder do PCFR (Partido Comunista da Federação Russa) que, na virada do século, mostrou-se o maior partido da Rússia, tanto em termo de filiados/militantes como em eleitores. ${ }^{2}$ É extremamente interessante acompanhar sua carreira política, pois ela exprime, de maneira emblemática, os principais dilemas e contradições por que passa o movimento comunista na Rússia pós-soviética. Acusado por alguns de tentar reviver um socialismo herdeiro do stalinismo e por outros de ser um oportunista abandonando os princípios tradicionais do comunismo por um mero parlamentarismo socialdemocrático, a figura de Zyuganov representa a encruzilhada em que se encontram os comunistas russos obrigados a se recompor em uma nova realidade onde devem escolher entre reforma ou revolução, classe ou nação, nacionalismo ou internacionalismo, retomar rumos do passado ou tentar um caminho completamente novo em direção ao socialismo.

Para se entender a trajetória atual desse líder político é necessário retornar às origens do próprio movimento comunista russo atual. No período fi- 
nal da perestroika o monolitismo do Partido Comunista da União Soviética (PCUS) já estava bastante fendido. Apesar da proibição formal de frações internas, surgiram as chamadas plataformas (de propostas ao Congresso partidário) que, na prática, começaram a funcionar como autênticas tendências com políticas próprias. Essas plataformas seriam os embriões de vários dos futuros partidos comunistas do período pós-soviético. Assim, além da corrente principal gorbachevista havia a Plataforma Bolchevista (stalinista, fundada na primavera de 1991, mas oriunda do movimento intrapartidário U nidade, criado em maio de 1989), a Plataforma D emocrática (formada em janeiro de 1990 e que apoiava uma ida mais rápida à economia de mercado e ao pluripartidarismo) e a Plataforma M arxista (criada em abril de 1990, eque propunha um social ismo-comunismo do tipo humanista). Zyuganov (um apparatchik do PCUS, com formação universitária em matemática e filosofia) participaria, em junho de 1990, da criação de um outro tipo de entidade que atuaria ativamente na luta intrapartidária: o PC RSFSR (Partido Comunista da República Social ista Federativa Soviética Russa), constituído para ser a seção especificamente russa dentro do multinacional PCUS. Atéali o PCUS tivera seções internas específicas para cada uma das quinze repúblicas da U nião Soviética, exceto a Rússia. A razão dessa exceção era que, como o PCUS tinha sua sede em M oscou e naturalmente a maior parte de seus quadros era constituída de russos (a maioria da população), não havia necessidade de uma seção específica para a Rússia. Entretanto, quando durante o decorrer da perestroika as nacionalidades das outras repúblicas começaram a demonstrar atitudes cada vez mais autonomistas, os comunistas russos começaram a clamar por uma seção própria para a República Russa também. Gorbachev, algo a contragosto, acederia a tais pretensões.

O PC RSFSR seria o embrião do futuro PCFR pós-soviético, portanto essas condições de criação do PC RSFSR marcariam profundamente Zyuganov e os outros futuros líderes que fundariam o PCFR em janeiro de 1993: uma oposição ao curso gorbachevista de enfraquecimento dos poderes centrais da URSS e um certo nacionalismo especificamente pró-russo mesclado às idéias do socialismo internacionalista.

$M$ as isso veremos posteriormente. N este momento, o principal é dizer que o PC RSFSR atuaria decisivamentena luta política dentro efora do PCUS. Lutaria pela preservação da URSS e do socialismo e contra as tendências centrífugas nas repúblicas. No caótico período final da URSS, quando fal hou, em agosto de 1991, a tentativa de golpe de al guns membros do governo (contra Gorbachev e a favor da manutenção da integridade da U RSS), o presidente 
da república russa, Boris Yeltsin, aproveitou para colocar na ilegalidade tanto o PC RSFSR quanto o PCUS, cujos dirigentes foram acusados de terem apoiado o putsch. O período do fim oficial da URSS (em dezembro de 1991) marcaria as tentativas de um grupo de antigos dirigentes comunistas (incluindo Zyuganov) de questionar nos tribunais a constitucionalidade destes decretos deYeltsin. Após longa batalha, em novembro de 1992, o Tribunal Constitucional pronunciou seu veredito: considerou constitucional a proibição do funcionamento dos órgãos dirigentes do PCUS e do PC RSFSR, mas inconstitucional a proibição de funcionamento dos órgãos de base do PC RSFSR. Estava aberto o caminho para a refundação do PC RSFSR a partir de suas estruturas locais de base. Uma campanha foi iniciada neste sentido e, em 13-14 de fevereiro de 1993, ocorreu um Congresso em que o PC RSFSR foi recriado com o nome de Partido Comunista da Federação Russa (PCFR). Zyuganov seria el eito presidente do Comitê Executivo Central, a posição máxima na hierarquia.

A fundação do PCFR traria à baila, já de início, al gumas das futuras controvérsias que marcariam a carreira de Zyuganov. M uitos dos antigos militantes e dirigentes comunistas queriam desafiar as proibições formais da justiça burguesa e simplesmente recriar o partido bolchevista-leninista na ilegal idade por toda a área da antiga URSS, independentemente do que dissesse o Tribunal Constitucional. Zyuganov preferiu o caminho mais seguro: recriar o PCFR pelas vias legais e estritamente dentro dos limites da nova Rússia, deixando de lado, por enquanto, as antigas repúblicas (onde freqüentemente havia proibições contra organizações eleitorais baseadas em outros países). Assim, uma das características da carrei ra de Zyuganov seria exatamente esta: a atuação dentro dos limites da legalidade, evitando "arroubos" revolucionários mais ousados.

Isso Ihe valeria a inimizade de vários outros constituintes do movimento comunista russo pós-soviético. Entre a colocação na ilegalidade do PCUS e do PC RSFSR após o putsch de agosto de 1991 ea criação do PCFR, em janeiro de 1993, outros partidos comunistas haviam sido formados. Os principais eram: o RKRP (Partido O perário Comunista da Rússia; de comunismo ortodoxo e obreirista), o VKPB (Partido Comunista Bolchevista de Toda a União; stalinista) e o RPK (Partido dos Comunistas da Rússia; de tendência inicial a um comunismo de caráter humanista e mais soft que o do RKRP eVKPB). Todos esses partidos se proclamavam revolucionários e criticaram duramente a ênfase legalista do PCFR. A rixa aumentaria mais ainda quando, em outubro de 1993, após longo conflito com o poder legislativo, o presidente Bo- 
ris Yeltsin fechou o Parlamento à força (aliás, literalmente a bala...). . A Rússia teria agora outro regime político através de uma Constituição mais presidencialista e um novo parlamento, cuja câmara baixa (a D uma) teve sua primeira eleição marcada para dezembro de 1993.

Os partidos comunistas revolucionários imediatamente denunciaram 0 novo regime e estabeleceram um boicote contra a eleição. Já o PCFR, apesar de denunciar o novo regime, resolveu participar do processo eleitoral. Quando as urnas foram abertas, o PCFR tinha recebido 12 por cento dos votos nas listas partidárias, ficando em terceiro lugar. ${ }^{3} \mathrm{Assim}$, o resultado de todo o período de crise de 1993 foi a desunião do movimento comunista pós-soviético. De um lado, o PCFR adquiriu status de maior PC do país (em função de ser o herdeiro das estruturas organizacionais do PC RSFSR e de seu relativamente bom desempenho na el eição para a Duma), e de outro os partidos mais revolucionários, agrupados no fórum coordenativo Roskomsoyuz (englobando RKRP, RPK, VKPB e outros), que acusavam o PCFR de conseguir seu sucesso ao preço de se amoldar ao sistema.

Essa divisão se aprofundaria com o passar do tempo. Os partidos menores, mais revolucionários, procurando chegar às massas, mas ficando presos em nichos especializados de grupos profissionais específicos, grevistas e outros, e o PCFR crescendo em termos eleitorais, mas mantendo um perfil bem mais soft e basicamente parlamentar. A eleição seguinte para a D uma (em dezembro de 1995) representou um salto qualitativo enormenessa direção. Nela, o PCFR foi o partido mais votado. O cupava sozinho acima de um terço das cadeiras da Duma, e o bloco do PCFR com seus aliados chegava a alcançar quase metade das vagas. Isto aumentou tremendamente o prestígio de seu líder, Zyuganov, para a corrida presidencial programada para 1996.

A eleição presidencial de 1996, desde o início marcada pela disputa entre Yeltsin e Zyuganov, assumiu caráter de plebiscito entre social ismo e capitalismo. Embalado pela recente vitória eleitoral do PCFR e pela crise econômica do país que abalava o prestígio de Yeltsin, Zyuganov parecia ter reais chances de chegar ao poder. Com este fim, para ameal har votos daquela parcela da população que normalmente não votava comunista, mas que estava desiludida com a crise econômica do país sob Yeltsin, Zyuganov moderou seu discurso. Evitava falar diretamente em comunismo e socialismo e enfatizava os aspectos de reforma no programa de seu partido. Além disso, para fazer frente à crescente invasão cultural e econômica estrangeira no país, assumiu discurso francamente nacionalista, de defesa da pátria russa, de modo a formar um bloco com todas as forças progressistas do país em defesa dos interesses nacionais. 
Aqui devemos abrir parênteses. 0 termo 'nacionalismo', no Brasil, pode ter dois sentidos: um positivo, como "defesa dos interesses da pátria contra imperialismo estrangeiro", e outro negativo, denotando xenofobia em relação a outros povos. Na Rússia, desde os tempos soviéticos, o termo nacionalismo (natsi onalizm) é tradicionalmente ligado ao segundo sentido, negativo. Por isso, é importante neste momento frisar, em defesa de Zyuganov, que ele sempre afirmou que sua posição não era a favor do nacionalismo (doutrina da afirmação da superioridade de uma nacionalidade sobre as outras) e sim do patriotismo (ou seja, da defesa dos interesses de sua pátria, a Rússia, e de todos que vivem nela). ${ }^{4}$

Esse discurso de ênfase na defesa dos interesses da pátria já era forte no PCUS desde sua fundação. A própria D eclaração Programática do Congresso Refundador, de 1993, terminava com as seguintes palavras:

A principal idéia reunificadora dos comunistas russos que vivem este momento histórico é a idéia do patriotismo, da integridade do Estado russo. Nossos objetivos: 0 interesse do povo, o florescimento e a grandeza da pátria! Na nossa bandeira: Pátria, Poder Popular e Socialismo. ${ }^{5}$

Zyuganov era o líder da corrente patriótica no partido. Sua ascendência prática na organização, como presidente do Comitê Executivo Central, seria acompanhada, no período 1993-1995, pela publicação de uma série de livros e artigos que exporiam sua visão do tipo de marxismo necessário à Rússia dos anos 90. Essas incursões teóricas chegariam a seu apogeu na primavera de 1995, quando Zyuganov defendeu tese de doutorado na faculdade de filosofia da Universidade de M oscou intitulada Os mecanismos e tendências básicas das mudanças sócio- políticas na Rússia contemporânea. A pesar de a tese ter sido defendida depois do III Congresso do partido, grande parte da Weltanschauung de Zyuganov já se tornava conhecida através de três livros seus que foram publicados entre 1993 e 1995: Drama V lasti ("O Drama do Poder"), de 1993, Derzhava ("Grande Potência"), de 1994, e Za Gorizontom ("Além do H orizonte"), de 1995. Uma versão condensada, popular, da tese de doutorado de Zyuganov foi publicada em 1995 sob o título Rossiya i Sovremennyi M ir ("A Rússia e o M undo Contemporâneo"). Nessas obras, além das idéias comunistas tradicionais, o autor apresentava al guns conceitos próprios bastante controversos do ponto de vista do marxismo ortodoxo. Zyuganov enfatizava o caráter único e especial da civilização eurasiana, continental, da Rússia e como esta era diferente das civilizações ocidentais "oceânicas" (como os Estados Unidos e a Inglaterra, por exemplo), com as quais se vê freqüentemente em conflito. ${ }^{6}$ Ele via a cultura política dessa civilização como "a expressão de 
uma tradição moral e histórico-cultural cujos valores fundamentais são o "coletivismo, sobornost' [ "comunalismo"] e gosu darstvennost' [ "Estadismo"] e a busca da corporificação dos mais altos ideais de bondade ejustiça". ' Além disso, o presidente do PCFR afirmava que os maiores veículos de transmissão desses valores eram os grupos étnicos, as nacional idades. "O s sujeitos das civilizações, seus transmissores e protetores, o principal agente no palco da história mundial têm sido sempre, desde a antigüidade, os grupos étnicos: nações e povos ...".

A esta altura, já se pode notar como as sobrancel has de diversos marxistas mais ortodoxos podiam estar levantadas. Tradicionalmente, o marxismo sempre deu ênfase aos conflitos de classe por sobre os conflitos nacionais. Esta ênfase nos grupos étnicos e na questão nacional quase que como um "motor" (ou, pelo menos, o motorista do carro) da história poderia parecer uma "heresia" dentro do marxismo. Principalmente quando juntada à visão que Zyuganov dava da história russa pré e pós-Revolução de O utubro. Para Zyuganov, "a Rússia corporifica seu próprio tipo especial de civilização, herdeira e continuadora da tradição milenar da Rus kieviana, do czarismo moscovita, do império russo e da União Soviética". ${ }^{9}$ Esse el o de continuidade era assegurado pelo fato de que, em todas estas épocas, os russos estavam unidos pelos valores comuns aqui já arrolados de coletivismo, sobornost' e gosudarstvennost'. O esforço de Zyuganov de congregar seus concidadãos em torno da "idéia russa" era tanto que chegava a afirmar:

No nível da ideologia política, um dos meios mais fortes de reprimir a autoconsciência nacional da Rússia ... são as constantes tentativas de contrastar antagonisticamente, na mente das pessoas, os ideais nacionais "vermelho" e "branco" ... Tenta-se convencer a opinião pública de que os períodos "pré-revolucionário" e "soviético" da nossa história são polarmente opostos, irreconciliáveis na forma e no conteúdo ...

A reunificação do ideal "vermelho" da justiça social ... com o ideal "branco" do Estado nacional ... dará à Rússia, finalmente, harmonia social ... ${ }^{10}$

Essa foi a parte em que Zyuganov mais chegou perto de uma "heresia" no campo dos ensinamentos marxistas tradicionais a fim de acomodar sua idéia do problema do Estado nacional como central. Para se entender isto, é preciso notar a atmosfera ideológica dos anos em que esses textos foram escritos. 0 período do desfecho da perestroika e imediatamente após a desintegração da União Soviética em finais de 1991 foi extremamente difícil para os comunistas. 0 "acerto com o passado" stalinista e soviético fora ideologicamente perturbador durante a perestroika, quando muitos russos, deslumbra- 
dos com as promessas de liberdade e abundância econômica espelhadas das democracias liberais ocidentais avançadas, viraram as costas ao comunismo ortodoxo. Assim, perante a dificuldade de entusiasmar as massas russas apenas com um apelo "de solidariedade de classe" nos moldes marxistas tradicionais, Zyuganov parecia querer fazer uma "adaptação" dos ideais comunistas russos clássicos em direção a englobar o componente "nacional", que assumia uma importância cada vez maior no imaginário popular. O u seja, se estava difícil mobilizar as massas somente com apelos "de classe", então que os comunistas não deixassem a "carta" nacional apenas nas mãos da direita e sim que a utilizassem também para tornar seu jogo mais eficiente.

O bviamente, essa ênfase no problema nacional e a aposta no fortalecimento do Estado russo para protegê-lo da invasão cultural e econômica estrangeira não poderia encontrar acolhida fácil em um movimento comunista tradicionalmente marcado pelos princípios do internacionalismo proletário e do Estado burguês como inimigo (até mesmo destinado a desaparecer, e não a se fortalecer, durante o comunismo...).

Quando instado pela esquerda sobre que tipo de caminho ao socialismo/comunismo realmente propunha o PCFR, as respostas de Zyuganov seguiam o padrão explicitado no programa do partido adotado em seu III Congresso (de janeiro de 1995), que dizia o seguinte:

0 partido contempla três etapas no caminho conseqüente para al cançar pacificamente seus objetivos.

Na primeira etapa, os comunistas organizam a defesa, pel os trabalhadores, de seus interesses políticos, econômicos esociais elideram as manifestações de massa dos trabalhadores pelos seus direitos ... O partido, junto com seus aliados, realiza a formação de um governo de salvação nacional ... Nesta etapa mantém-se a estrutura plural [de propriedade] na economia, condicionada pelo nível das forças produtivas...

Na segunda etapa, após alcançar uma relativa estabilidade econômica e política, os trabal hadores conseguirão participar cada vez mais ativamente e largamente da administração dos negócios do Estado através dos sovietes, sindicatos, auto-gestão operária e outros órgãos de governo popular direto que tomem vida. Na economia sensivelmente assumirão papel dirigente as formas socializadas de administração econômica que são, socialmente, estruturalmente e técnico-organizacional mente mais bem adaptadas para prover o bem-estar do povo. Este será o período de transição e reconstrução.

A terceira etapa marca a formação definitiva, na infra-estrutura econômica, das relações socialistas que correspondam às exigências do modelo de desenvol- 
vimento socialista ótimo. Predominarão as formas sociais de propriedade nos meios de produção.

Nós definimos o socialismo pleno (na expressão de Lenin) como a sociedade sem classes, livre da exploração do homem pelo homem, e que divide seus frutos e bens de acordo com a quantidade, qualidade e resultado do trabalho ...

No socialismo estão contidos e se desenvolvem os pré-requisitos essenciais da futura associação comunista ... ${ }^{11}$

Assim, fica caracterizada uma concepção etapista, evolucionista, legalista e pacífica ao socialismo. As tarefas imediatas do partido para deter o destrutivismo da política entreguista de Yeltsin seriam a formação de uma frente de salvação nacional, em que o PCFR participaria junto com outros partidos de esquerda e de centro quetivessem uma plataforma progressista e patriótica.

O resultado final de todas essas "concessões" feitas pelo PCFR e por Zyuganov durante suas campanhas eleitorais foi um alargamento do número de votantes à sua direita no espectro, concomitantemente a um aumento do fosso entre ele e os partidos comunistas mais revolucionários (alguns dos quais só o apoiaram no segundo turno e, mesmo assim, a contragosto). Eleitoralmente a estratégia de Zyuganov foi relativamente bem sucedida em termos do movimento comunista como um todo. Zyuganov só foi derrotado por Yeltsin no segundo turno após uma disputa apertadíssima, na qual os empresários do país financiaram uma campanha milionária de propaganda para manter o presidente da Rússia em seu posto.

Assim, no período após a eleição parlamentar de 1995 e a presidencial de 1996, o PCFR se firmava como o maior partido do país, tanto em termos de militância e filiados como de votos. Isto ficava mais realçado graças à fragilidade do nascente quadro partidário da Rússia. A maioria das organizações eleitorais não tinha uma base sólida e muitos foram criados como meras plataformas el eitorais para determinados candidatos, desaparecendo logo depois (por exemplo, o N ossa Casa éa Rússia, que apoiava o primeiro-ministro Viktor Chernomyrdin, e o Unidade, que posteriormente elegeria Putin). Entre os outros grandes partidos mais votados, apenas o Yabloko (liberal) e o LDPR (neofascista, de Zhirinovskii) revelaram-se estáveis ao longo de toda a década. À esquerda do PCFR estavam os partidos comunistas revolucionários (como o RKRP - o segundo maior do país - , o VKPB e o RPK) que, apesar de uma atuação militante em greves e demonstrações de rua, não conseguiam superar a barreira eleitoral de 5 por cento para el eger deputados para a Duma pelas listas partidárias. ${ }^{12}$

O u seja, no período entre as eleições parlamentares de 1995 e 1999, a 
Rússia viveu sob a tensão de um poder executivo mais forte constitucionalmente (mas enfraquecido pela crise econômica do país) e um parlamento maisfraco, mas com uma sólida presença da esquerda, cujo núcleo era o PCFR. A permanente crise estrutural era tão forte que, até 1999, em todos os anos o incremento do PNB do país tinha sido negativo (com a única exceção de 1997, quando a economia cresceu mísero 0,8 por cento).$^{13}$ Esta situação chegou ao auge na crise cambial de agosto de 1998, quando o rublo despencou. M as essa situação de "fundo do poço" talvez tenha sido salutar para a Rússia. Ela colocou a nu a impossibilidade de se manter um modelo de capitalismo baseado em especulações financeiras e em exportação das matérias-primas das quais o país era tão rico. 0 primeiro-ministro Primakov, chamado às pressas para resolver a situação, declarou que a Rússia passaria a dar mais atenção ao setor produtivo e diminuir a exposição aos riscos do capitalismo especulativo. De qualquer maneira, a Rússia adentrava 1999 em má forma, o que dava grandes esperanças ao PCFR de conseguir excelentes resultados na eleição parlamentar de 1999 e na presidencial de 2000. ${ }^{14}$

É nesse momento que entra em cena o chamado fenômeno Putin. Passado o troca-troca de ministros que se seguiu à crise cambial de agosto de 1998, Yeltsin finalmente escolheu seu primeiro-ministro definitivo em agosto de 1999: V ladimir Putin. Na época, foi uma surpresa para a imprensa, pois Putin não era um político, não parecia ter muito carisma (fala de maneira algo maquinal eburocrática). M as isto acabou se encaixando bem no perfil da imagem nova que se queria apresentar ao público: uma pessoa "de fora", que não tinha participado da política especulativa suja dos anos 90, um pragmático ex-espião do KGB com perfil "militar", capaz de "pôr ordem na casa”. Além disso, era jovem e praticante de esportes, o que dava um certo ar de refrescante dinamismo comparado com o estilo algo "naftalínico" e "etílico" de Yeltsin. M as o que real mente foi um turning-point que elevou o durão Putin a alturas de herói nacional foi sua reação aos atentados a bomba contra prédios residenciais na Rússia que mataram dezenas de civis em setembro de 1999, supostamente causados por terroristas islâmicos. Utilizando sua experiência nos serviços de segurança, Putin agiu com vigor contra os guerrilheiros islâmicos no Daguestão e ordenou a invasão da Chechênia, até então virtual território livre para os separatistas. Ao contrário da impopular guerra contra a Chechênia de 1994-1996, nesta o grosso da população apoiava Putin no bojo da indignação diante da morte de quase trezentos civis nos atentados ter roristas. Esta segunda campanha foi executada de forma militarmente mais eficiente: primeiro bombardeando maciçamente a região e apenas depois enviando tropas terrestres, o que diminuiu as impopulares mortes entre os 
soldados. A finalização relativamente rápi da e eficiente dessa "guerra justa" elevou o prestígio de Putin. Afinal, nada melhor que uma guerrinha externa bem-sucedida para resolver problemas de política interna, diriam os mais cínicos...

A sorte de Putin com os el eitores estava reforçada pelo fato de que, em 1999, a economia russa teve um crescimento positivo de 5,4 por cento. 0 fato de, sob Putin, o PNB do país ter crescido 5,4 por cento em 1999 e 8,3 por cento em 2000 contribuiria sobremaneira para elevar sua popularidade, pois passava a impressão de que bastou ele ter assumido o governo para a Rússia voltar a crescer, após uma década de decréscimo econômico. ${ }^{15}$ Sem desmerecer as possíveis virtudes de Putin no comando dessa retomada econômica, devese destacar que grande parte dela se deveu ao aumento dos preços do petróleo e gás (dos quais a Rússia é grande exportadora) e também a uma natural retomada de crescimento após o "fundo do poço" de uma década inteira de decréscimo econômico (semelhante aos conhecidos booms pós-guerras).

Todo esse quadro atrapal hou completamente os planos dos comunistas. $\mathrm{Na}$ avalanche de popularidade pró-Putin, o PCFR conseguiu ainda obter 0 maior número das 450 cadeiras da Duma eleita em dezembro de 1999 (113), mas tinha proporcionalmente menos delas em relação aos outros partidos. $\mathrm{E}$ os dois outros partidos mais votados (o recém-criado pró-Putin Unidade e 0 Pátria-Toda a Rússia, deYurii Luzhkov), que obtiveram respectivamente 72 e 66 cadeiras, se fundiriam em 2001 no chamado Rússia Unida (o que teoricamente lhes dava bancada parlamentar maior que a do PCFR a partir daí). $\mathrm{Na}$ eleição presidencial de março de 2000, Putin não deu chance a Zyuganov, sendo eleito ainda no primeiro turno com mais de 50 por cento dos votos. ${ }^{16}$

Ou seja, na virada do século, os comunistas russos estão em um momento delicado, uma verdadeira encruzilhada. Por um lado os partidos revolucionários continuam ainda pequenos el eitoral mente e confinados em guetos especializados. A recuperação da economia permitiu uma maior oferta deempregos e uma regularização dos salários e pensões atrasados, o que diminui 0 potencial de insatisfação contra o governo. Por outro, o PCFR, e Zyuganov em particular, viram Putin abocanhar uma fatia de seu próprio discurso, levando com isso parte de seu eleitorado. Refiro-meà questão da defesa do Estado nacional russo. Como vimos anteriormente, Zyuganov utilizava esse discurso não-tradicional entre os comunistas como forma de aumentar seu raio de influência para fora das bases classistas tradicionais. Entretanto, Putin, oriundo dos antigos órgãos de segurança soviéticos, utilizou também esta retórica, passando a imagem do homem jovem, pragmático, durão, que fortaleceria o Estado russo, tirando-o da si tuação de prostração e impotência em 
que se encontrou na maior parte da década de 1990. A poiado nos resultados práticos obtidos na campanha contra a Chechênia e na recuperação do crescimento econômico positivo, Putin obteve resultados eleitorais expressivos. Legitimado por esse sucesso el eitoral, criou uma sólida base (algo fisiológica) de apoio na nova Duma que Ihe tem permitido realizar uma série de reformas centralizadoras que dão maior poder ao presidente e ao centro contra as tendências centrífugas nas localidades. Tudo isto criou um aparente ambiente de maior ordem no país o que, por sua vez, consolida sua imagem de presidente de pulso forte e que realmente está fortificando o Estado russo.

Ora, se essa era uma das bandeiras de Zyuganov, pode-se notar que Putin está conseguindo atrair para o seu campo votos que antes gravitavam em direção ao líder comunista. A situação causou confusão dentro do próprio PCFR, que se viu tendo que votar a favor de uma série de medidas centralizadoras de Putin com as quais os comunistas tinham concordância. M as a luade-mel com o novo presidente logo terminaria eZyuganov tentaria puxar o PCFR para a oposição novamente. Como ele afirmou no VII Congresso do PCFR, de dezembro de 2000,

o PCFR escolheu adotar em relação a Putin uma atitude comedida: vejamos se ele provará realmente a seriedade das intenções declaradas. É claro que sempre criticando as ações do poder executivo ... que provocam danos ao povo e ao Estado.

Entretanto, Putin já está há mais de um ano no poder e constatamos que as esperanças dos russos na mudança do curso político não se realizaram. É claro que a retórica patriótica ... não é de todo má [mas] passos concretos para a meIhoria da situação não são dados.

O governo atual dança sob a música do FM I ... Constroem-se planos para liquidar as últimas garantias sociais dos trabal hadores...

Como, então, devemos nos comportar em relação ao presidente?

Até hoje o partido se manteve sob a fórmula: “Atos positivos: apoiamos. Atos danosos: criticamos". E todos os passos que podem ser exigidos de uma oposição construtiva nós demos ...

Esperar mais não faz sentido. Por isso o PCFR afirma novamente o seu papel de oposição responsável e irreconciliável à política capitalista destrutiva. ${ }^{17}$

Sobre as acusações (vindas dos partidos revolucionários à sua esquerda) de que o PCFR estaria dando mais ênfase à ideologia do patriotismo que ao socialismo, Zyuganov disse: 
[Estas acusações] partem do princípio que a plataforma ideológica do PCFR "reúne" em si dois tipos de vertentes: a social ista ea patriótica. Isto é um engano.

0 patriotismo não éum sistema ideológico separado, mas, como disse Lenin, "um dos mais profundos sentimentos, consolidado através dos séculos e milênios" ...

H oje, na Rússia, existem patriotas sinceros, que demonstram seus sentimentos em formas monárquicas, nacionalistas, burguesa-liberal e outras formas com freqüência anti-comunistas. E o que devemos fazer? Empurrá-los para longe por isso? N ão, isto seria uma asneira política. Lenin enfatizava que seria ingênuo achar que todos chegariam a uma consciência socialista "unicamente pela linha marxista". Cada um chega lá da sua maneira ... Pelo trabal ho em comum ... poderemos demonstrar que fora da escolha socialista a Rússia não se manterá nem como comunidade de povos, nem como totalidade histórico-cultural, nem como civilização única ... O socialismo é a forma contemporânea do patriotismo na Rússia ... [e] o socialismo autêntico está organicamente impregnado de altos sentimentos patrióticos, não sendo concebível sem eles. ${ }^{18}$

Zyuganov fazia questão de diferenciar o patriotismo dos comunistas do de Putin:

0 regime vigente emprega cada vez mais uma fraseologia patriótica. Entretanto, na prática, as idéias de Estado forte são castradas e colocadas a serviço dos interesses da oligarquia. Um 'Estado forte' junto com uma política liberal é uma linha reta em direção a um regime militar-policial ... N ós partimos do pressuposto de que o fortalecimento do Estado não é o fortalecimento do aparel ho repressivo e burocrático. Um real fortalecimento do Estado significa o estabelecimento de um genuíno poder popular, controle popular sobre o aparelho de Estado e a mudança de política a favor dos interesses da maioria trabalhadora. ${ }^{19}$

Sobre a questão de uma possível unificação entre os diversos partidos comunistas, Zyuganov reafirmou a posição do PCFR (que é considerada por alguns dos outros partidos como "elitista" em relação às agremiações comunistas menores):

N ossa posição sobre este problema já vem de longa data e é conhecida: a unidade é conseguida em ações comuns, na luta em comum dos comunistas. E esta unidade se consegue em quase todas as regiões da Rússia, onde há muito tempo já não se ouve falar do notório "multipartidarismo comunista”. E, no que tange a uma série de grupos e círculos de M oscou, que se denominam "partidos", a experiência de muitos anos demonstrou: os "processos de unificação", iniciados 
por eles, não levam a nada, a não ser dissensão e disputas. Eles apenas atrapaIham práticas concretas ...20

\section{CONCLUSÃo}

Como vimos, na figura de Zyuganov estão entrelaçados al guns dos dilemas mais marcantes do movimento comunista russo atual. Volta ao passado ou busca de um socialismo total mente novo no futuro? M anutenção de uma postura comunista ortodoxa ou busca de posições social-democratas? Nacionalismo ou internacionalismo? Priorizar a questão de classe ou a questão nacional?

Conseguirão os comunistas russos integrar dialeticamente estes pólos diferentes ou continuarão a se equilibrar entre um e outro sem conseguir um ponto de apoio sólido?

A atuação de Zyuganov à frente do maior partido comunista da Rússia atual demonstra o delicado estado de transição em que se encontram os comunistas russos e forma uma espécie de pivô em torno do qual giram as expectativas da possi bilidade de uma volta - ida? - a uma sociedade de cunho socialista no maior país do mundo.

\section{NOTAS}

${ }^{1}$ Este artigo é baseado em entrevistas pessoais e pesquisa direta na Rússia no período em que o autor cursou mestrado no Instituto Pushkin de Moscou (1989-1992) e quando lá voltou, na virada do século, para a pesquisa de sua tese de doutorado sobre a perestroika (defendida na Universidade Federal Fluminense). Como alguns dos documentos citados neste artigo podem ser encontrados nas homepages oficiais dos partidos russos na Internet, 0 autor procurou, sempre que este for o caso, indicar a URL de tais sites nas notas bibliográficas.

${ }^{2}$ Mesmo atualmente, o PCFR ainda éo maior partido da Rússia em termos de filiadose, especialmente, de militantes. Em termos eleitorais, o PCFR foi o partido mais votado nas ultimas eleições para a Duma ( 1995 e 1999). Em 18 de dezembro de 2001, as organizações que tiraram segundo etercei ro lugar na eleição de 1999 (Unidade e Pátria) se fundiram no partido Rússia Unida, o que teoricamentelhes dá, juntas, a maior bancada parlamentar.

${ }^{3}$ Tsentral'naya Izbiratel'naya Komissiya [ "Comissão Eleitoral Central" - homepage com hyperlinks para os resultados eleitorais oficiais de diversos anos]: www.fci.ru. 
${ }^{4}$ Sobre isto, ver as afirmações claras de Zyuganov em sua entrevista a Evgenii Kiselyov, transcrita no jornal Sovetskaya Rossiya, 13 jun. 1996, p.3. A expressão que Zyuganov usa para descrever sua posição é patriotismo estatal.

${ }^{5}$ PROGRAM M N OE Zayavlenie: II Chrezvychainogo Sez'da Kommunisticheskoi Partii Rossiiskoi Federatsii [ "Declaração Programática: II Congresso Extraordinário do Partido Comunista da Federação Russa"]. Sovetskaya Rossiya, 2 mar. 1993, p.2.

${ }^{6}$ ZYU GAN OV, G. Derzhava [ "Grande Potência”]. M oscou: Informpechat', 1994, p.63-4; .Za Gorizontom ["Além do horizonte"]. Orel:VeshnieVody, 1995, p.74.

${ }^{7}$ Ibidem.

${ }^{8}$ Ibidem, p.10.

${ }^{9}$ Ibidem, p.74.

${ }^{10}$ ZYU GAN OV, op. cit., 1994, p.124-5.

${ }^{11}$ KOM M UNISTICHESKAYA PARTIYA ROSSIISKOI FEDERATSII ["Partido Comunista da Federação Russa"]. Programma Kommunisticheskoi Partii Rossiiskoi Federatsii ["Programa do Partido Comunista da Federação Russa"]. In: PASH ENTSEV, E. N. (O rg.) O ppozitsionnye Partii i D vizheniya Sovremenoi Rossii. M oscou: Informpechat', 1998, p.34-5.

${ }_{12}$ Para aqueles interessados em conhecer mais detalhes sobre os partidos comunistas póssoviéticos (além do PCFR) recomendo a leitura de meu livro Herdeiros de Lenin: a história dos partidos comunistas na Rússia pós-soviética (a ser lançado muito brevemente pela editora 7Letras).

${ }^{13}$ Economist Intelligence U nit - Country Report: Russia (versão eletrônica), diversos anos.

${ }^{14}$ Para uma análise detal hada da longa crise econômica russa nos anos 90 ver SEGRILLO, A. O Fim da U RSS ea Nova Rússia. Petrópolis: Vozes, 2000.

${ }^{15}$ Economist..., cit.

${ }^{16}$ Tsentral'naya..., cit.

${ }^{17}$ Politicheskii Otchet Tsentral'nogo Komiteta KPRF VII S"ezdu i O cherednye Zadachi Partii ["Relatório Político do ComitêCentral do PCFR ao VII Congresso eas Tarefas Imediatas do Partido"]. M oscou: PCFR, 2000, pt. I.3, disponível em: www.kprf.ru/arhiv/congr7/ 7szd_doklad1.htm.

${ }^{18}$ Ibidem, pt. II.2.

${ }^{19}$ O cherednye Zadachi KPRF [ "As Tarefas Imediatas do PCFR"]. M oscou: PCFR, 2000. Disponível em: www.kprf.ru/arhiv/congr7/7szd_zadachi.htm.

${ }^{20}$ Politicheskii..., cit., pt. II.2.

Artigo recebido em 06/2003. Aprovado em 10/2005 